\title{
用匀浆互补法测试杂种优势的研究 (I)
}

\author{
杨福愉史宝生 那菁如赵 连 元 \\ （中国科学院生物物理研究所）（张家口坝下农业科学研究所） \\ 拱浻昕任落 \\ (北京农业科学院作物研究所)
}

杂种优势的利用是提高农作物产量的有效途径之一，但强优势杂交种的获得一般都是在 田间组配大量杂交组合与多年产量比较的基础上才能获得. 因此人们都希望找到一些有效的 生理、生化指标来予测亲本组合的杂种优势以缩短选育良种的年限和减轻工作量. 1966 年美 国 McDaniel ${ }^{[1]}$ 等人提出用线粒体互补法来予测杂种优势(即): 能产生杂种优势的两个亲本的 线粒体于离体条件下混合时，它们的活性超过任何一个亲本). 但后来英国、西德等国家的一 些科学工作者并没有重复出 $\mathrm{McDaniel}$ 的实验结果 ${ }^{[2-3]}$. 近年来我国也有不少单位开展这方面 的工作. 从大多数实验结果来看, 也没有获得象 McDaniel 那样明显的结果 ${ }^{[4-7]}$. 从 1977 年 初开始我们尝试用种籽黄化幼苗的匀浆替代线柆体，对玉米和谷子杂种优势与匀浆互补作用 的相关性进行了研究. 实验的初步结果表明, 大多数具有明显杂种优势的玉米和谷子组合的 亲本幼苗匀将化活性均有显著的互补作用，而杂种优势不明显的组合则不表 现出 互 补现 象.

\section{一、玉米匀藻互补突验}

具有明显杂种优势的组合都系经过小区实验和大面积生产鉴定的种釈. 张单九号 (张系 $5 \times$ 金 02) 由张家口坝下农业科学研究所制种. 京单 402 (黄早四 $\times N 6$ ), 京早 7 号(黄早四 $\times$ 罗系 3), 京单 403 (黄早四 $\times \mathrm{C} 103 \mathrm{R}$ ), 京早 6 号(华 ${ }_{4-11-4} \times \mathrm{Cr}_{25-3-2}$ )、京单 401 (黄早四 $\times$ 796) 由北京农业科学院作物研究所玉米组供种. 中单 2 号 (自 $330 \times \mathrm{Mo17}$ ) 系中国农业科学 院农业研究所玉米组供种. 成单 4 号 (Oh43 $\times$ 矮广 10),成单 3 号 (门可比 $\times$ 金 03) 由四川

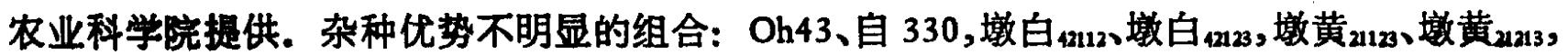
由北京农业科学院作物研究所玉米组提供, $\mathrm{F}_{83} \times(03 \times 27 \mathrm{~A})_{212}$ 由北京市延庆县农业科学研 究所提供,公社好、门 14 由四川雅安农业局提供.

种籽发芽时,先将干净种籽用 $0.1 \%$ 氯化永浸泡 10 分钟灭菌, 经清水冲洗半小时, 再在水 中浸泡 15 小时左右, 然后均匀平铺在有纱布的搪瓷盘内. 在 $2^{\circ} \mathrm{C}$ 的恒温箱中发芽 $2-3$ 天. 为了使亲本和杂交种萌发幼苗的长度尽可能一致，不同种籽催芽的时间可以根据具体情况加 以掌招. 在整个发芽过程中注意控制温度，黄化幼苗剪下后在冰箱中放置 1 小时，然后倒入 双层的尼龙袋中以 $1: 3$ 的比例加入匀浆介质 $(0.25 \mathrm{M}$ 蔗糖, $0.067 \mathrm{M}$ 磷酸缓冲液 $\mathrm{pH} 7.2,0.005 \mathrm{M}$ 
EDTA， 0.75 毫克牛血清清蛋白 $/ \mathrm{ml}$ ，在姿觔中磨碎，过滤除去残渣. 上述操作都在低温下进 行. 之后将过滤液用冷冻离心机进行离心 $(1000 \times \mathrm{g}, 10$ 分钟 $)$ 取上清液. 两个亲本的幼苗 匀浆按 $1: 1$ 比例在 $0^{\circ} \mathrm{C}$ 互补 30 分钟. 匀浆氧化活性的测定用瓦氏测压法. 反应介质内含：匀 浆 $1.3 \mathrm{ml}, 0.2 \mathrm{M} \alpha$ 酮戊二酸 $0.2 \mathrm{ml}, 0.06 \mathrm{M} \mathrm{Mgcl}_{2} 0.1 \mathrm{ml}$ ，匀浆介质 $1.3 \mathrm{ml}$ ，反应液总体积 $2.9 \mathrm{ml}$, 反 应温度 $28^{\circ} \mathrm{C}$, 平衡 5 分钟, 测定 30 分钟.

杂种优势比较显著的 9 个组合的玉米黄化幼苗匀浆互补测定结果总结于表 1. 从表 1 中 可以看出，除成单 4 号和京早 7 号外，其余组合的杂种幼苗匀浆的耗氞值都高于其亲本. 此 外,两个亲本幼苗匀浆的互补现象在 9 个组合中有 7 个组合比较显著. 这些结果表明,与线柆 体相比较, 杂种优势明显的玉米幼苗匀浆氧化活性的互补现象要明显得多 ${ }^{[7-8]}$, 而杂种优势不 明鼠的五个组合的亲本幼苗匀浆的氧化活性都不表现出互补现象 (表 2). 在五个组合中, 有

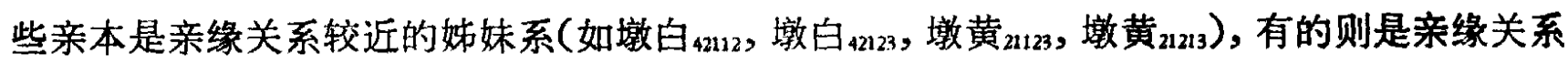
比较远的组合 [如 $F_{83} 、(03 \times 27 A)_{212}$ ].

表 1 杂种优势明显的玉米幼苗匀浆的氧化活性

\begin{tabular}{|c|c|c|c|c|c|c|}
\hline \multirow{2}{*}{ 组合名称 } & \multicolumn{2}{|c|}{ 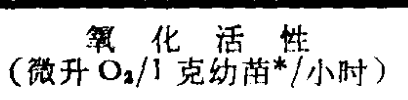 } & \multirow{2}{*}{\multicolumn{2}{|c|}{ 组合名称 }} & \multicolumn{2}{|c|}{ 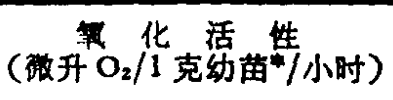 } \\
\hline & & 相对比值 ** & & & & 相对比值 ${ }^{* *}$ \\
\hline 张系 5 & \multirow{4}{*}{$\begin{array}{l}135.5^{* * * *} \\
99.6 \\
195.5 \\
174.6\end{array}$} & \multirow{4}{*}{$\begin{array}{l}1.66 \\
1.48\end{array}$} & \multirow{2}{*}{\multicolumn{2}{|c|}{$\begin{array}{l}\text { 京单 } 403 \quad(x) \\
\text { 黄早四 +C103R } \quad(+)\end{array}$}} & \multirow{2}{*}{$\begin{array}{l}144.1 \\
105.9\end{array}$} & \multirow{3}{*}{$\begin{array}{l}1.77 \\
1.30\end{array}$} \\
\hline 金 02 ( & & & & & & \\
\hline 张单九号 $\quad(x)$ & & & \multirow{5}{*}{\multicolumn{2}{|c|}{$\begin{array}{|cc|}\text { 华 4-11-4 } & (9) \\
\text { Cr25-3-2 } & \left(0^{7}\right) \\
\text { 京早六号 } & (x) \\
\text { 华 } 4-11-4+\operatorname{Cr} 25-3-2(+)\end{array}$}} & \multirow{5}{*}{$\begin{array}{r}76.9 \\
96.3 \\
110.7 \\
98.9\end{array}$} & \\
\hline 张系 $5+$ 会02 (+) & & & & & & \multirow{4}{*}{$\begin{array}{l}1.28 \\
1.14 \\
\end{array}$} \\
\hline 贵早四 & \multirow{4}{*}{$\begin{array}{l}249.6 \\
276.4 \\
289.0\end{array}$} & \multirow{4}{*}{$\begin{array}{l}1.21 \\
1.26\end{array}$} & & & & \\
\hline$\left(\sigma^{7}\right)$ & & & & & & \\
\hline 京单 402 & & & & & & \\
\hline 黄早四 $+N_{6}(+)$ & & & \multirow{4}{*}{$\begin{array}{l}\text { 黄早四 } \\
796 \\
\text { 京单 } 401 \\
\text { 黄早四 }+796 \\
\end{array}$} & & \multirow{4}{*}{$\begin{array}{l}119.8 \\
109.2 \\
138.9 \\
155.4\end{array}$} & \multirow{4}{*}{$\begin{array}{l}1.21 \\
1.35\end{array}$} \\
\hline 自 330 & 55.1 & \multirow{4}{*}{$\begin{array}{l}1.41 \\
1.37\end{array}$} & & 0 & & \\
\hline Mol7 & \multirow{3}{*}{76.7} & & & & & \\
\hline 中单 2 号 & & & & $(+)$ & & \\
\hline 自330+Mo17(t) & & & \multirow{4}{*}{$\begin{array}{l}\text { Oh43 } \\
\text { 矮广 } 10 \\
\text { 成单 } 4 \text { 号 } \\
\text { Oh } 43+\text { 矮广 } 10\end{array}$} & (q) & \multirow{4}{*}{$\begin{array}{r}108.8 \\
94.5 \\
102.5 \\
120.2\end{array}$} & \multirow{4}{*}{$\begin{array}{l}1.00 \\
1.18\end{array}$} \\
\hline 黄早四 & 86.2 & \multirow{4}{*}{$\begin{array}{l}1.08 \\
1.26\end{array}$} & & & & \\
\hline 罗系 3 & \multirow{3}{*}{$\begin{array}{l}100.9 \\
118.1\end{array}$} & & & & & \\
\hline 京早七兵 & & & & $(+)$ & & \\
\hline 黄早四+罗系 3(+) & & & 门可比 & (q) & 64.9 & \multirow{3}{*}{$\begin{array}{l}1.33 \\
1.01\end{array}$} \\
\hline 黄早四 & 81.2 & & 成单 3 号 & $(x)$ & 107.4 & \\
\hline C:103R & 81.2 & & 门可比 + 金 03 & $(+)$ & 81.7 & \\
\hline
\end{tabular}

*以蛋白质含暴来比较等化活性得到相似结果。

**系与亲本平均值之比.

****表中所列数值都系至少两次测定结果的平均值。 
表 2 杂种优势不明显的玉米幼苗多浆的保化活性

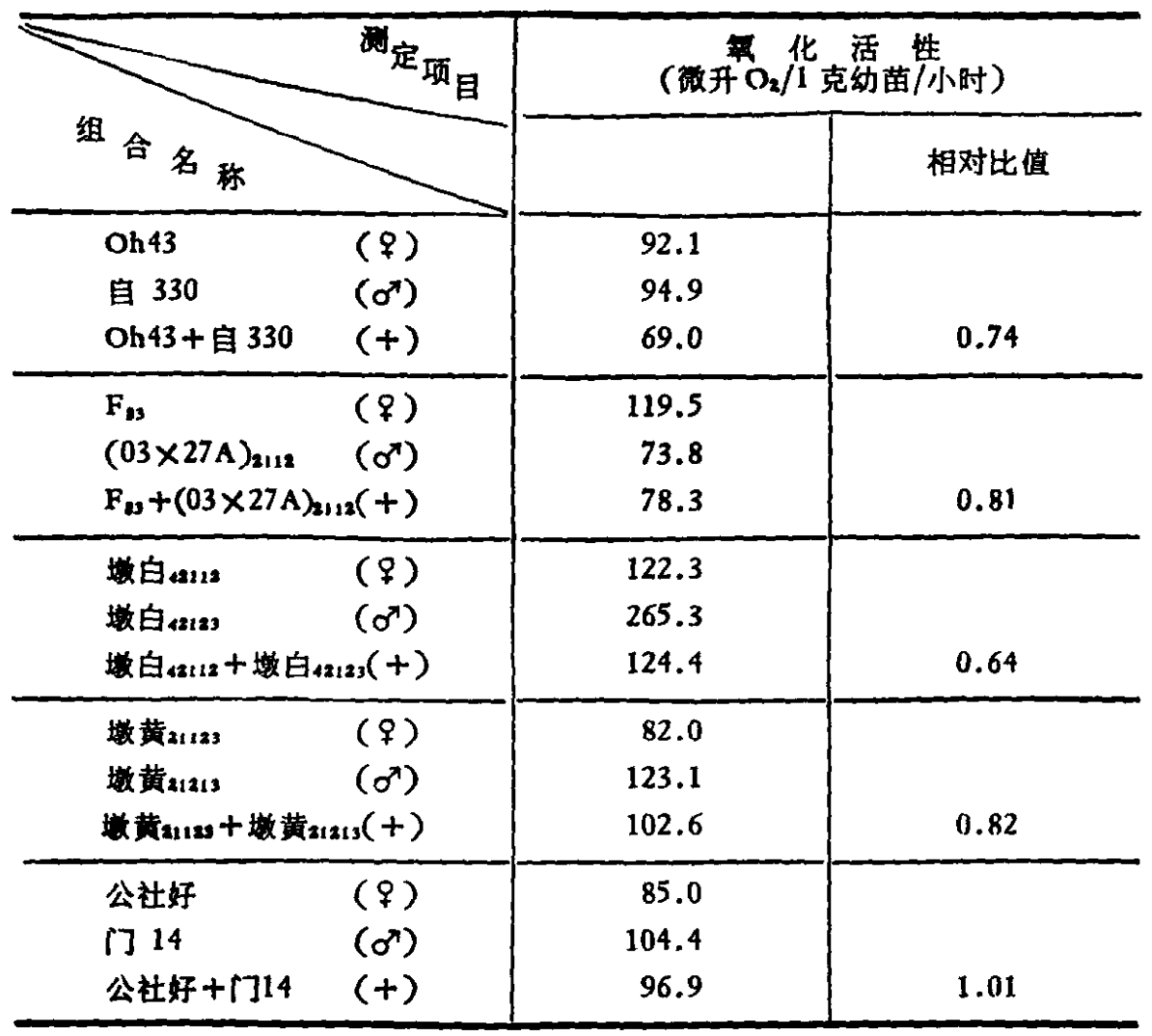

\section{二、谷子幼苗匀浆互补实验}

谷子幼苗匀浆互补实验材料中两个组合是杂种优势较明显的：蒜系 $28 \times$ 承谷 5 号和日 本 60 日、张农 9 . 另外是两个杂种优势不明显的组合：蒜系 28 、张农 11 和蒜系 $28 \times$ 压塌 耧,后者小区实验表现出杂种优势 ${ }^{[8]}$ ，但经大面积生产鉴定为杂种优势不明显的组合.

谷子发芽和制备幼苗匀浆基本与玉米相似. 匀浆介质组分为: 蔗糖 $0.125 \mathrm{M}$, 磷酸缓冲液 0.067M pH7.2, EDTA0.005M. 其它实验步骤与测试方法基本上与玉米匀浆互补实验相似.

谷子匀浆实验结果表明, 有杂种优势的谷子幼苗匀浆的耗氧值明显高于亲本. 两个亲本 的幼苗匀浆在体外等比混合后也表现出显著的互补作用 (表 3). 杂种优势不很明显的两个组 合: 蒜系 28、张农 11 和蒜系 28、压塌楼的幼苗匀浆则没有明显的互补现象(表 4).

表 3 杂种优势明显的谷子幼苗匀浆的草化活性

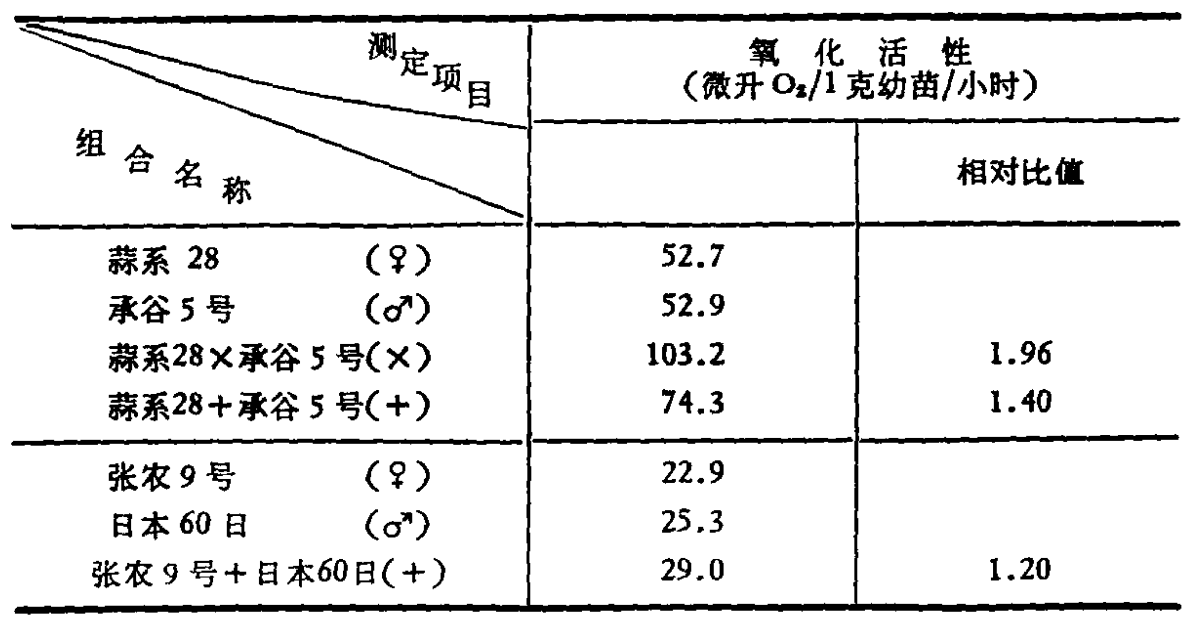


表 4 杂种优势不明显的谷子幼苗匀浆的氧化活性

\begin{tabular}{|c|c|c|c|}
\hline \multirow{2}{*}{\multicolumn{2}{|c|}{ 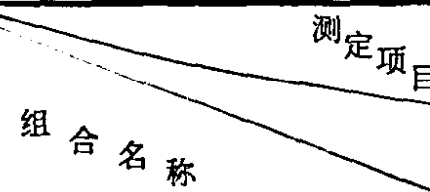 }} & \multicolumn{2}{|c|}{ （微升 $\mathrm{O}_{2} / 1$ 克幼苗/小时） } \\
\hline & & & 相对比值 \\
\hline 蒜系 28 & $(q)$ & 139.3 & \\
\hline 张农 11 & $\left(\sigma^{7}\right)$ & 95.8 & \\
\hline 蒜系 $28+$ 张农 11 & $(+)$ & 120.0 & 1.02 \\
\hline 蒜系 28 & $(q)$ & 105.9 & \\
\hline 压塌楼 & $\left(\sigma^{7}\right)$ & 78.2 & \\
\hline 蒜系 28+压堨耧 & $(+)$ & 93.8 & 1.02 \\
\hline
\end{tabular}

综上所述,我们的初步实验结果表明,无论玉米还是谷子幼苗匀浆的互补现象与杂种优势 具有比较显著的相关性. 但是实验的组合还不够多,因此还须要进行更多的工作来加以验证. 与线粒体互补法相比较,应用匀浆互补法来测试农作物杂种优势还具有：种籽用量少、方法简 便等优点. 值得注意的是，种籽纯度、种籽储存条件和时间、发芽条件等等因素都会影响互补 作用的实验结果. 因此在进行幼苗匀浆互补实验时应尽量用纯度较高的种秄作为实验材料, 亲本和杂交种的种籽最好是同一年制种的. 种籽发芽时亲本和杂交种的幼苗长度应尽量相一 致(约 $1.5-2.0$ 厘米).

我们的初步实验结果表明, 杂种优势明显的幼苗匀浆互补要比线粒体互补明显得多. 广 东植物研究所曾报道 ${ }^{[5]}$ 将杂种优势亲本幼苗分离出的线粒体进行等量混合，不表现出明显的 互补现象. 如果先将亲本的幼苗或幼苗匀浆进行等量混合然后再分离其线粒体, 互补现象就 比较显著. 从我们测试的大多数具有杂种优势的玉米组合来看, 匀浆互补是一个客观存在的 事实. 这个过程的作用机理是什么? 根据上述情况，似乎不应仅考虑线粒体与线柆体之间的 作用，而应该研究匀浆中其它组分与线粒体之间的相互关系. 由此我们对匀浆互补机理作了 初步的探讨 ${ }^{[9]}$.

\section{考文嗝}

[1] MeDaniel, R. G. et al., Science, 152 (1966). 1640.

[2] Ellis, J. R. S. et al., Nature, 241 (1973), 45.

[ 3 ] Zobe, R. G. et al., Plant Physiol., 50 (1972), 790.

[4] 浙江农业大学植物生理教研组, 植物学报, 17 (1975), 9, 250.

[5] 广东樎物研究所生理生化研究室, 植物研究, 1976, 4, 12 .

[ 6 ] 上海植物生理所光合作用研究室二组, 植物学报, 19 (1977), 3, 216.

[ 7 ] 中国科学院生物物理研究所三空二组, 生物化学与生物物理进展, $1978,1,1$.

[8] 中国科学院生物物理所三室二组, 1977 年全国细胞培美与体细胞杂交、线粒体呼吸代谢与杂种优势会议集.

[9]杨福愉、邢蓄如, 科学通报, 24 (1979), 待发表。

[上接 751 页]

[1]王清和、朱汉城、赵忠仁、同德全,植物保护学报, 1964，3，195-198.

[2] 中国科学院上海生物化学研究所病帮组、山东省果树科学研究所瓷病研究组, 中国科学, 1974, 6, 622-626.

[3] 中国科学院上海生物化学研究所病组、江苏省至业研究所桑树保护组,中国科学, 1974, 3, 283-291.

[4] 中国科学院上海生物化学研究所病毒组、渐江雀农业科学院峑桑研究所病虫害组, 中国科学, 1974, 3, 292-296. 